\title{
The eminence status of bacterial pigments under different aspects
}

\author{
Parisa Sabbagh, Amirmorteza Ebrahimzadeh Namvar \\ Department of Microbiology, School of Medicine, Babol University of Medical Sciences, Babol, Iran
}

\begin{abstract}
Summary
Several bacteria such as Flavobacterium, Serratias, Chromobacterium and Streptomyces that produce different pigments are playing a significant role in various fields of sciences. Alternatively, current knowledge about bacterial pigments is limited to medical bacteriology, for instance their importance in virulence factors and protective features, however recently the investigators have revealed the supplementary consequence of pigments in food, textile and pharmaceutical aspects.
\end{abstract}

\section{Introduction}

The pigments play a critical aspect amongst various organisms in environmental interactions fields, difference in gender and the presence of some special features. However, the existence of pigments' variation in micro-organisms is considered to be in relation with the evolution of the selective pressures (18). Pigments have an important role in physiology and molecular process of microorganisms; for example, assist in adapting to environmental conditions, sunlight protection, photosynthetic or in the classification and taxonomy of bacteria (54). The name of bacterial pigments is often derived from the microorganism's name, in which Rosenbach (1884) proposed the golden pathogen and non-pigmented staphylococci as S. aureus and Staphylococcus albus

Correspondence: Amirmorteza Ebrahimzadeh Namvar, Department of Microbiology, School of Medicine, Babol University of Medical Sciences, Babol, Iran.

E-mail: amirmorteza.namvar@gmail.com

Key words: Bacteria, pigments, industrial, virulence factor.

Contributions: the authors contributed equally.

Conflict of interest: the authors declare no potential conflict of interest.

Received for publication: 21 December 2017.

Accepted for publication: 27 December 2017.

(C) Copyright P. Sabbagh and A.E. Namvar, 2017

Licensee PAGEPress, Italy

Microbiologia Medica 2017; 32:7247

doi:10.4081/mm.2017.7247

This article is distributed under the terms of the Creative Commons Attribution Noncommercial License (by-nc 4.0) which permits any noncommercial use, distribution, and reproduction in any medium, provided the original author(s) and source are credited. respectively. Also, the rarely found blue-green Pseudomonas species in cystic fibrosis patients were called Pseudomonas aeruginosa, which is mainly Latina and means a rusty copper color (18). The purpose of this review is about pigments various roles in bacterial function and also in different sciences such as chemistry, biotechnology and pharmaceutical industry.

\section{The chemical composition of pigments and growth conditions}

Pigments diversity depends on differences in their chemical structure and also the presence of special chromophores (10). An unsaturated organic molecule contains a group of single or double bonds that serves the changes of light absorption to lower frequencies (longer wave lengths). The presence of these substances, results in the creation of the desired color. Indeed, the assortment of these materials, which is commonly called root color, creates the extended spectrum colors like Beta Carotene, Lycopene and Anthocyanin (64). Pigment production and biosynthesis are associated with a variety of factors like the environmental and culture conditions, $\mathrm{PH}$, inorganic phosphate concentration, temperature, etc. (75). For instance production of prodigiosin pigment will increase in Peptone Glycerol Broth and Nutrient Broth from $28^{\circ} \mathrm{C}$ up to $30^{\circ} \mathrm{C}(20,37)$.

\section{Pigment-producing bacteria}

Some of the most important pigment-producing bacteria are: Agrobacterium aurantiacum, Serratia marcescens, Chromobacterium violaceum, Micrococcus spp. and Pseudomonas aeruginosa. According to the conducted investigations, Gram-negative bacilli produce a wide range of bacterial pigments (57).

\section{Important pigments produced by bacteria}

Some of considerable pigments which are produced with bacteria are as follow: Zeaxanthin, the yellow pigment of Flavobacterium sp, Astaxanthin the pinkish pigment of Agrobacterium aurantiacum, Yellow carotenoid pigment of $M$. varians and M. luteus, Orange carotenoid pigments in M. nishinomiyaensis, Pink carotenoid pigment in M. roseus and M. agilis, Prodigiosin, the red pigment in Serratia marcescens and other bacteria, Violacein, the purple pigment in Iodobbacter, Chromobacterium violaceum, Janthinobacterium, Pyocyanin, the blue-green pigment in Pseudomonas aeruginosa and Actinorhodin, the blue pigment in Streptomyces coelicolor $(4,36,53,62,73)$. 


\section{The pigments performance and features}

Recently, the usages of pigments in a several range of industries (food industry, intinction and drug production) have been increased (70). Natural colors can be obtained from sundry sources, including ore, insects, plants and microbes in which the plants and microorganisms are the most useful, because of their sustainability in color production and culture situation $(3,29,35)$. Among microbes, bacteria are especially regarded for their highest potential. So producing and also using of bacterial pigments as natural colors have been studied by many researchers, although this issue is currently considered as one of the studied fields for different industrial purposes $(13,16,24)$.

\section{Protective aspect}

Protecting against heat and cold, UV ray and also containing anti-microbial, anti-cancer and anti-oxidant properties (30).

\section{Food industry}

Usage of natural colors in the food industry has been increased generally. These pigments have been replaced by synthetic dyes (5). Some microorganisms that are capable for producing high efficiency pigments are as follow: Monascus, Serratia, Paecilomyces, Cordyceps and Streptomyces (60). It should be noted that Riboflavin, Beta-Carotene and Phycocyanin have high performances in traditional fermented food industry (63).

\section{Pharmaceutical industry}

Many of bacterial pigments have been respected as antibiotics and immunosuppressive agents due to their high clinical and research potentials or for treating a variety of diseases such as cancer, leukemia, diabetes that can be noticed as below.

\section{Anthocyanins}

A flavonoids water-soluble pigment, with a wide range of biological activities consists of antioxidant, reduction of the risk of cancer, regulation of the immune response as well as reduction of inflammation $(25,50,59)$.

\section{Prodigiosin}

A pinkish linear trypyrrole pigment with cytotoxic and $\mathrm{T}$ cell suppressive activities $(56,67)$.

\section{Metacyclo-prodigiosin}

Desmethoxy prodigiosin and Prodigiosin 25-C: This pigment has anti-malarial, antibiotic, immunosuppressive and anti-biofilm activities $(11,78)$. Yoshida and colleagues have showed that cycloprodigiosin hydrochloride; similar to other prodigiosins can promote $\mathrm{H}^{+} / \mathrm{Cl}^{-}$symport which may lead to cytosol acidification and resulting in cell death process $(8,72)$. Other hypotheses about the pigment's functions were suggested by Songia et al. (44). They found that the rise of preventing of human lymphocytes proliferation is conducted by inhibiting the retinoblastoma phosphorylation and suppression depending on kinase 2 and 4 . Scientists have found that this pigment stimulates apoptosis in sw-620 and DLD1 that causes mutations or defects in the p53 function (39).

\section{Astaxanthin}

A red-orange pigment that is produced by the fungus, yeast, Agrobacterium aurantiacum, and Xanthophyllomyces dendrorhous (76). This pigment has health benefits in the prevention of cardio- vascular diseases, enhancing the human immune system, bioactivity against $H$. pylori and prevention of cataracts due to its high antioxidant activity $(38,74)$.

\section{Violacein}

A purple pigment that can be produced by several bacterial species. This pigment has the antitumor, antiparasitic, antiprotozoal, anti-cancer, antiviral, antibacterial and furthermore antioxidant activities $(12,23,40)$. The antitumor mechanism of this pigment is still being studied, and it has been recently shown that the mentioned pigment activates the apoptosis in HL60 (leukemia) cell line and p38 MAPK through the activation of caspase- 8 and transcription of NF-KB. The pigment's toxicity in colorectal cancer cell line, (HT29) has been evaluated. In addition, blocking the G1 phase, up-regulation in p53, p27, and p21 levels, decrease cyclin D1 expression in the cell cycle are the violacein pigment other consequences (42). Anti-mycobacterial activity of violacein pigment produced from Janthinobacterium $s p$. and yellow-orange Flexirubin pigment gained from Flavobacterium $s p$. were studied by Mojib et al. $(12,40,42,47)$.

\section{As an inhibitor}

The following pigments can be mentioned as a number of those which are respected as an inhibitor factor: i) The yelloworange flexirubin pigment produced by Flavobacterium sp. with the bactericidal activity against $E$.coli and $B$. cereus. It seems that this antibacterial activity is more effective in Gram positive bacteria (48). ii) Pyocyanin and Pyorubin produced by $P$. aeruginosa have antibacterial effects on Citrobacter $s p$ (68). iii) The orange pigment produced by Exiguobacterium aurantiacum that has antimicrobial activity against $E$. coli, Klebsiella $s p$., S. aureus and Erwinia sp (49). iv) Melanin, a dark color, water insoluble and resistant to concentrated acid, pigment by antimicrobial properties and also protecting against UV, solar and gamma rays $(17,21)$. The antibacterial function of melanin in protecting bacteria is still unknown. Recently a recombinant plasmid containing tyrosinase gene has been manipulated in E. coli that induces the melanin in tyrosine supplemented medium, whereas this role of melanin hasn't been proved yet in $P$. aeroginosa in in-vitro $(6,15,52)$.

\section{Textile industry purposes}

Microorganisms produce a large variety of stable pigments like Carotenoids, Flavonoids, and Quinones. In addition, some natural colors, especially anthraquinones compounds, show the significant antibacterial activity, so they are capable to be used as anti-microbial dyes in textile industries. Alihosseini et al. described that the red prodigiosin pigment achieved from Vibrio strains is used as the color for wool, nylon, silk and acrylic fibers $(1,43,66)$. A study conducted by Yusof demonstrated that the Serratia marcescens prodigiosin is applied for dyeing in acrylic fabric, micropolyester, polyester, silk and cotton (51). Ahmad et al. described that violacein pigment produced by Chromobacterium violaceum is used as different fabric dyes like silk, cotton, acrylic and polyester (24).

\section{As a virulence factor}

There is a proven relationship between pigments and virulence factors in several bacteria, so the most important ones are mentioned as below.

\section{Staphyloxanthin}

Is a carotenoid pigment which is produced in the biosynthetic pathway by $S$. aureus. Many studies have shown that deletion of the gene encoding the CrtM enzyme in the initial biosynthesis of 
Staphyloxanthin produces the bacteria without pigments and more sensitivity to death by human neutrophils respectively (51). The gene which encoding this pigment is regulated by operon CrtOPQMN (45). It is noteworthy that 4', 4'-diaponeurosporene is considered as a secondary biosynthetic compound. Transferring of both CrtM and CrtN genes from $S$. aureus to other genus of bacteria will lead to synthesis of the 4', 4'-diaponeurosporene. This topic has been investigated in mouse models (51). Compared to wild strains, non- pigmented mutants of $S$. aureus are more sensitive to death by hydrogen peroxide, superoxide, hydroxyl radicals, hypochlorite and oxygen $(45,51)$.

\section{Pyocyanin}

Many species of Pseudomonas spp. produce blue, green pigment of Pyocyanin (41). Many studies indicate that non-pigmented mutant of $P$. aeruginosa is mostly ineffective on both acute and chronic lung infection model in mice. This pigment has considerable toxic properties in a wide range of target organisms, comprising bacteria, yeasts, insects, nematodes, and plants $(33,69)$. One of these mechanisms is inhibition of cellular respiration (46). On the other hand, the ability of changing redox cycle and increasing oxidative stress causes harmful varied effects on the host cells, for instance disturbing the $\mathrm{Ca}^{2+}$ homeostasis in human respiratory epithelial cells. While, $\mathrm{Ca}^{2+}$ is important for ion transport regulation and mucus secretion, it is more likely to develop $P$. aeruginisa lung related infections (34). Other toxic effects of this pigment are respiratory cell disorders, inhibition of epidermal cell growth factors, prostaglandin release from epithelial cells and changing the balance of protease and anti-proteases activity in cystic fibrosis (2).

\section{Violacein}

Oxidation and bounding of two L-tryptophan molecules by VioA and VioE enzymes produce pyrrolidone and, eventually, Violacein (7). This pigment has powerful antioxidant properties and may protect lipid membrane against peroxidation that induced by hydroxyl radicals (75). Evaluating of this pigment as a chemotherapeutic agent shows that it is capable to induce leukocytes apoptosis (7).

\section{Granadaene of group B Streptococcus}

Granadaene is one of the main causes of neonatal infections is Group B streptococcus, which can produce the red-orange pigments (31). Though, recent reports have shown that ornithine rhamno-polyene pigment structure with 12 conjugated double bonds is called granadaene and increases survival in macrophages (65). Additionally related studies demonstrated that, Streptococcus pigmented strains may lead to systematic related infections. Also the mentioned pigment may have the virulence function $(50,77)$.

\section{As a marker}

The emergence of violacein pigment with Flexibacter and Sporocytophaga imply on water contamination (14,22). As well the non-blue pigment of Vogesella indigofera illustrates the chromium contaminated sites because this bacterium produces blue pigment in normal conditions but in $\mathrm{Cr}^{6+}$ contaminated areas, the related encoding genes expression is inhibited which is defined as a bacterial defense system $(19,71)$.

Currently, pigment biosynthesis can be regulated by molecular techniques and genetic engineering with expression and inhibition of responsible genes (9). A blue actinorhodin pigment produced by Streptomyces coelicolor can be lead to the production of bright yellow Kalafungin by using of genetic modification techniques (61). This method is performed for modification of acti- norhodin pigment to Anthraquinones $(26,28)$. Production of bacterial pigments such as Prodigiosin and Violacein is controlled by the Quorum sensing system $(32,58)$. Finally it should be noted that pigments produced by bacteria are removable by using different solvents and their features are detectable with various techniques: Thin-layer chromatography (TLC), Ultraviolet-visible spectroscopy (UV-Vis), Fourier transform infrared spectroscopy (FTIR), Electrospray ionization mass spectrometry (ESI-MS), Nuclear magnetic resonance (NMR), and High performance liquid chromatography (HPLC). Moreover the spectroscopy of various pigments is available by Raman Spectroscopy. Nowadays, extracting the pure and concentrated bacterial pigments is a major challenge of technology $(27,55)$.

\section{Conclusions}

In conclusion, despite of our hypothesis about bacterial pigments, these components have both pathogenesis factors and beneficial aspects.

\section{References}

1. Ahmad AS, Ahmad WYW, Zakaria ZK, et al. Applications of bacterial pigments as colorant, the Malaysian perspective. New York: Springer Briefs in Molecular Science; 2012.

2. Alihosseini F, Ju KS, Lango J, et al. Antibacterial colorants: characterization of prodiginines and their applications on textile materials. Biotechnol Prog 2008;24:742-7.

3. Austin DA, Moss MO. Numerical taxonomy of red pigmented bacteria isolated from a lowland river, with the description of a new taxon, Rugamonas rubra gen. J Gen Microbiol 1986;132:1899-909.

4. Balibar CJ, Walsh CT. In vitro biosynthesis of violacein from L-tryptophan by the enzymes VioA-E from Chromobacterium violaceum. Biochemistry 2006;45:15444-57.

5. Bartel PL, Zhu CB, Lampel JS, et al. Biosynthesis of anthraquinones by interspecies cloning of actinorhodin biosynthesis genes in streptomycetes: clarification of actinorhodin gene functions. J Bacteriol 1990;172:4816-26.

6. Bhosale P. Environmental and cultural stimulants in the production of carotenoids from microorganisms. Appl Microbiol Biotechnol 2004;63:351-61.

7. Charkoudian LK, Fitzgerald JT, Khosla C, et al. In living color: bacterial pigments as an untapped resource in the classroom and beyond. PLOS Biol 2010;8:e1000510.

8. Clauditz A, Resch A, Wieland KP, et al. Staphyloxanthin plays a role in the fitness of Staphylococcus aureus and its ability to cope with oxidative stress. Infect Immun 2006;74:4950-3.

9. Cole SP, Rudd BA, Hopwood DA, et al. Biosynthesis of the antibiotic actinorhodin, Analysis of blocked mutants of Streptomyces coelicolor. J Antibiot 1987;40:340-7.

10. Denning GM, Railsback MA, Rasmussen GT, et al. Pseudomonas pyocyanine alters calcium signaling in human airway epithelial cells. Am J Physiol 1998;274:L893-900.

11. Frandsen RJN, Nielsen NJ, Maolanon N, et al. The biosynthetic pathway for aurofusarin in Fusarium graminearum reveals aclose link between the naphthoquinones and naphthopyrones. Mol Microbiol 2006;61:1069-80.

12. Golubev WI. Perfect state of Rhodomyces dendrorhous (Phaffia rhodozyma). Yeast 1995;11:101-10. 
13. Gouterman M. Optical spectra and electronic structure of porphyrins and related rings. New York: Dolphin Academic; 1978. pp 1-165.

14. $\mathrm{Gu}$ JD, Cheung KH. Phenotypic expression of Vogesella indigofera upon exposure to hexavalent chromium, Cr6+. World J Microbiol Biotechnol 2001;17:475-80.

15. Han SB, Park SEH, Jeon Yj, et al. Prodigiosin blocks T cell activation by inhibiting interleukin-2R alpha expression and delays progression of autoimmune diabetes and collageninduced arthritis. J Pharmacol Exp Ther 2001;299:415-25.

16. Huang L, Pardee AB. Beta-lapachone induces cell cycle arrest and apoptosis in human colon cancer cells. Mol Med 1999;5:711-20.

17. Hui KM, Hurlbert RE. Modifiable chromatophore proteins in photosynthetic bacteria. J Bacteriol 1979;138:207-17.

18. Jacobson G, Wasileski J. Production of food colorants by fermentation. In: Gabelman A (ed.). Bioprocess production of flavour, fragrance, and colour ingredients. New York: John Wiley \& Sons; 1994. pp 205-237.

19. Kieser T, Bibb MJ, Buttner MJ, et al. Practical Streptomyces genetics. John Innes Foundation 2000.

20. Kim CH, Kim SW, Hong SI. An integrated fermentation separation process for the production of red pigment by Serratiasp, KH-95. Proc Biochem 1996;35:485-90.

21. Kim H, Han SB, Lee OW, et al. Use of prodigiosin for treating diabetes mellitus. US Patent 2003;6:638-68.

22. Konzen M, Marco DD, Cordova CAS, et al. Antioxidant properties of violacein: possible relation on its biological function. J Bioorg Med Chem 2006;14:8307-13.

23. Lau GW, Goumnerov BC, Walendziewicz CL, et al. The Drosophila melanogaster toll pathway participates in resistance to infection by the gram-negative human pathogen Pseudomonas aeruginosa. Infect Immun 2003;71:4059-66.

24. Lau GW, Hassett DJ, Ran H, et al. The role of pyocyanin in Pseudomonas aeruginosa infection. Trends Mol Med 2004;10: 599-606.

25. Lau GW, Ran H, Kong F, et al. Pseudomonas aeruginosa pyocyanin is critical for lung infection in mice. Infect Immun 2004; $72: 4275-8$.

26. Lazze MC, Savio M, Pizzala R, et al. Anthocyanins induce cell cycle perturbations and apoptosis in different human celllines. Carcinogenesis 2004;25:1427-33.

27. Lin WP, Lin WP, Lai HL, et al. Effect of melanin produced by a recombinant Escherichia coli on antibacterial activity of antibiotics. J Microbiol Immunol Infect 2005;38:320-6.

28. Liu GY, Doran KS, Lawrence T, et al. Sword and shield: linked group B streptococcal beta-hemolysin/cytolysin and carotenoid pigment function to subvert host phagocyte defense. Proc Natl Acad Sci USA 2004;101:14491-6.

29. Liu GY, Essex A, Buchanan JT, et al. Staphylococcus aureus golden pigment impairs neutrophil killing and promotes virulence through its antioxidant activity. J Exp Med 2005;202: 209-15.

30. Logan NA. Bacterial systematics. London: Blackwell Scientific; 1994. pp 60-61.

31. Lu X, Al-Qadiri HM, Lin M, et al. Application of mid-infrared and Raman spectroscopy to the study of bacteria. Food Bioprocess Technol 2011;4:919-35.

32. Madigan MT, Martinko JM, Parker J. Brock: Biology of Microorganisms, 9th ed. London: Prentice-Hall International; 2000. pp 573-589.

33. Malpartida F, Hopwood DA. Molecular cloning of the whole biosynthetic pathway of a Streptomyces antibiotic and its expression in a heterologous host. Nature 1984;309:462-4.
34. Martinko JM, Madigan MT. Brock biology of microorganism, 8th ed. Parker J, Prentice Hall International 2006.

35. Matz C, Deines P, Boenigk J, et al. Impact of violacein producing bacteria on survival and feeding of Bacterivorousnano flagellates. Appl Environ Microbiol 2004;70:1593-9.

36. McClean HK, Winson MK, Fish L, et al. Quorum sensing and Chromobacterium violaceum: exploitation of violacein production and inhibition for the detection of N-acylhomoserine lactones. Microbiology 1997;143:3703-11.

37. McDaniel R, Ebert-Khosla S, Hopwood DA, et al. Engineered biosynthesis of novel polyketides. Science 1993;262:1546-50.

38. McNulty H, Jacob RF, Mason RP. Biological activity of Carotenoids related to distinct membrane physiochemical interactions. Am J Cardiol 2008;101:D20-9.

39. Mohankumari HP, Naidu A, Vishwanatha S, et al. Safety evaluation of Monascus purpureus red mould rice in albino rats. Food Chem Toxicol 2009;47:1739-46.

40. Mojib N, Philpott R, Huang JP, et al. Antimycobacterial activity in vitro of pigments isolated from Antarctic bacteria. Antonie Van Leeuwenhoek 2010;98:531-40.

41. Moss MO, Ryall C. The genus Chromobacterium. In: The Prokaryotes. Berlin: Springer-Verlag; 1981. pp 1355-1364.

42. Nakamura Y, Sawada T, Morita Y, et al. Isolation of a psychrotrophic bacterium from the organic residue of a water tank keeping rainbow trout and antibacterial effect of violet pigment produced from the strain. Biochem Eng J 2003;12:79-86.

43. Nicholaus R, Piatelli M, Fattorusso E. The structure of melanins and melanogenesis_IV, on some natural melanins. Tetrahedron 1964;20:1163-72.

44. Nizet V. Streptococcal $\beta$-hemolysins: genetics and role in disease pathogenesis. Trends Microbiol 2002;10:575-80.

45. Liu GY, Essex A, Buchanan JT, et al. Staphylococcus aureus golden pigment impairs neutrophil killing and promotes virulence through its antioxidant activity. J Exp Med 2005; 202:209-15.

46. Nosanchuk JD, Casadevall A. The contribution of melanin to microbial pathogenesis. Cell Microbiol 2003;5:203-23.

47. Pankaj VR. Kumar R. Microbial pigment as a potential natural colorant for contributing to mankind. Res Trends Mol Biol 2016;85-98.

48. Parekh S, Vinci VA, Strobel RJ. Improvement of microbial strains and fermentation processes. Appl Microbio Biotech 2000;54:287-301.

49. Patel K, Wyman J, Patel K, et al. A mutant of Bacillus thuringiensis producing a dark-brown pigment with increased UV resistance and insecticidal activity. J Invertebr Pathol 1996;67:120-4.

50. Pryce LH, Terry FW. Spectrophotometric assay of gene expression: Serratia marcescens Pigmentation. Bioscience 2000;26:3-13.

51. Raisainen R, Nousiainen P, Hynninen PH. Dermorubin and 5chlorodermorubin natural anthraquinone carboxylic acids as dyes for wool. Textile Res J 2002;72:973-6.

52. Richard C. Chromobacterium violaceum, opportunist pathogenic bacteria intropical and subtropical regions. Bull Soc Pathol Exot 1993;86:169-73.

53. Rosa-Fraile M, Rodríguez-Granger J, Haidour-Benamin A, et al. Granadaene: proposed structure of the group B Streptococcus polyenic pigment. Appl Environ Microbiol 2006;72:6367-70.

54. Rosenbach FJ. Wund-Infections-Krankheiten des Menschen. Wiesbaden: Bergmann; 1884.

55. Rozhavin MA. Effect of Pseudomonas aeruginosa melanin on antibiotic activity. Antibiotiki 1978;23:718-20. 
56. Saha S, Thavasi R, Jayalakshmi S. Phenazine pigments from Pseudomonas aeruginosa and their application as antibacterial agent and food colourants. Res J Microbiol 2008;3:122-8.

57. Sánchez C, Braña AF, Méndez C, et al. Reevaluation of the violacein biosynthetic pathway and its relationship to indolocarbazole biosynthesis. Chem Bio Chem 2006;7:1231-40.

58. Sato T, Konno H, Tanaka Y, et al. Prodigiosins as a new group of $\mathrm{H}+/ \mathrm{Cl}-$ symporters that uncouple proton translocators. J Biol Chem 1998;273:21455-62.

59. Schindler PRG, Metz H. Bacteria of the Flexibacter Sporocytophaga group and violet-colored bacteria as indicators of hygienic hazardous drinking water. Zentralblatt Hygiene Umweltmedizin 1989;189:29-36.

60. Shatila F, Yousef H, Holail H. Pigment production by Exiguobacterium aurantiacum $\mathrm{FH}$, a novel Lebanese strain. Int J Curr Microbiol App Sci 2013;2:176-91.

61. Songia S, Mortellaro A, Taverna S, et al. Characterization of the new immunosuppressive drug undecylprodigiosin in human lymphocytes. J Immunol 1997;158:3987-95.

62. Sutthiwong N, Fouillaud M, Valla AC, et al. Bacteria belonging to the extremely versatile genus Arthrobacter as novel source of natural pigments with extended hue range. Food Resint 2014:65:156-62.

63. Stankovic N, Radulovic V, Petkovic M, et al. Streptomyces sp. JS520 produces exceptionally high quantities of undecylprodigiosin with antibacterial, antioxidative, and UV-protective properties. Appl Microbiol Biotechnol 2012;96:1217-31.

64. Stankovic N, Senerovic L, llic-Tomic T, et al. Properties and applications of undecyl prodigiosin and other bacterial prodigiosins. Appl Microbiol Biotechnol 2014;98:3841-58.

65. Tapsall JW. Pigment production by Lancefield-group-B streptococci (Streptococcus agalactiae). J Med Microbiol 1986;21: $75-81$.

66. Thomson NR, Crow MA, McGowan SJ, et al. Biosynthesis of carbapenem antibiotic and prodigiosin pigment in Serratia is under quorumsensing control. Mol Microbiol 2000;36: 539-56.
67. Tibor C. Liquid Chromatography of Natural pigments and synthetic dyes. J Chromatog Library 2007;71:11-9.

68. Unagul P, Wongsa P, Kittakoop P, et al. Production of red pigments by the insect pathogenic fungus Cordy cepsunilateralis BCC 1869. J Ind Microbiol Biotechnol 2005;32:135-40.

69. Vanessa Z, Cardona C. Molecular analysis, physiological study and biotechnological capabilities of blue pigmented bacteria fromPuerto Rico [Ph.D. dissertation]. University of Puerto Rico 2010.

70. Venil CK, Lakshmanaperumalsamy P. An insightful overview on microbial pigment: prodigiosin. Ele J Biol 2009;5:49-61.

71. Venil CK, Zakaria ZA, Ahmad WA. Bacterial pigments and their applications. Process Biochem 2013;48:1065-79.

72. Voggu L, Schlag S, Biswas R, et al. Microevolution of cytochrome bd oxidase in Staphylococci and its implication in resistance to respiratory toxins released by Pseudomonas. J Bacteriol 2006;188:8079-86.

73. Wang J, Mazza G. Effects of anthocyanins and other phenolic compounds on the production of tumor necrosis factor alpha in LPS/IFN gamma-activated RAW 264.7 macrophages. J Agric Food Chem 2002;50:4183-9.

74. Williamson NR, Fineran PC, Leeper FJ, et al. The biosynthesis and regulation of bacterial prodiginines. Nat Rev Microbiol 2006;4:887-99.

75. Wilson R, Sykes DA, Watson D, et al. Measurement of Pseudomonas aeruginosa phenazine pigments in sputum and assessment of their contribution to sputum sol toxicity for respiratory epithelium. Infect Immun 1988;56:2515-7.

76. Yoshida J, Takamura S, Nishio M. Characterization of a streptococcal antitumor glycoprotein (SAGP). Life Sciences 1998;62:1043-53.

77. Yuodim KA, McDonald J, Kalt W, et al. Potential role of dietary flavonoids in reducing microvascular endothelium vulnerability to oxidative and inflammatory insults. J Nutr Biochem 2002;13:282-8.

78. Yusof NZ. Isolation and applications of red pigment from Serratia marcescens. Universiti Teknologi Malaysia 2008. 